\title{
LIMITES E POTENCIALIDADES DO PLANEJAMENTO E DA GOVERNANÇA REGIONAL: A REGIÃO METROPOLITANA DO VALE DO PARAÍBA E LITORAL NORTE NA MACROMETRÓPOLE PAULISTA ${ }^{1}$
}

\author{
Rosa SCAQUETTI ${ }^{2}$ \\ Pedro Ribeiro MOREIRA ${ }^{3}$ \\ Lidiane MACIEL ${ }^{4}$
}

RESUMO: Esse artigo pretende contribuir para o debate acerca da capacidade que as Regióes Metropolitanas brasileiras teriam de praticar governança, ou seja, coordenar e integrar efetivamente o planejamento e a execução das funçóes públicas de interesse comum. O estudo focado na governança metropolitana se origina da constatação do descompasso entre as iniciativas de governança e as açôes efetivamente implementadas no contexto do estado de São Paulo no período da criação do Estatuto da Metrópole, ocorrido em 2015. Um espaço de observação possível dessas questóes é a Região Metropolitana do Vale do Paraíba e Litoral Norte (RMVPLN), situada na Macrometrópole Paulista, tendo em vista a sua diversidade, bem como a larga distância entre a data de sua proposição e a da sua institucionalização, significando um contexto complexo de variáveis para estudo. Investiga-se como se deram os processos de criação e institucionalização dessa Regiáo Metropolitana, desde as negociaçóes de institucionalização até a

\footnotetext{
1 O presente trabalho foi realizado com apoio da Coordenação de Aperfeiçoamento de Pessoas do Nível Superior Brasil (CAPES).

2 Universidade do Vale do Paraíba (UNIVAP), Instituto de Pesquisa e Desenvolvimento - São José dos Campos SP - Brasil. Doutora. ORCID: https://orcid.org/000-003-367-738X. rosamariascaquetti@gmail.com.

3 Universidade do Vale do Paraíba (UNIVAP), Instituto de Pesquisa e Desenvolvimento - São José dos Campos SP - Brasil. Docente pesquisador. ORCID: https://orcid.org/0000-0002-0659-5549. pedroribeiro@univap.br.

4 Universidade do Vale do Paraíba (UNIVAP), Instituto de Pesquisa e Desenvolvimento - São José dos Campos SP - Brasil. ORCID: https://orcid.org/0000-0002-5029-7645. lidiani.maciel@gmail.com.
} 
tentativa de consolidação da governança metropolitana, buscando desenvolver a hipótese de haver uma centralidade no que se chama de fato regional, em detrimento do fato metropolitano. A partir de uma pesquisa quanti-qualitativa descritiva, e utilizando-se de dados publicados por instituiçóes de pesquisa, mídias sociais e entrevistas, levantam-se os sentidos da criação da RMVPLN e coloca-se em perspectiva o processo de governança no contexto do planejamento em escala regional.

PALAVRAS-CHAVE: Planejamento regional; governança; regiāo metropolitana; Região Metropolitana do Vale do Paraíba e Litoral Norte (RMVPLN); macrometrópole paulista.

\section{LIMITS AND POTENTIALITIES OF METROPOLITAN REGION GOVERNANCE: THE CASE OF THE METROPOLITAN REGION OF VALE DO PARAÍBA E LITORAL NORTE IN THE SÃO PAULO MACROMETROPOLIS}

ABSTRACT: This article intends to contribute to the debate about the capacity of Brazilian Metropolitan Regions to practice governance, that is, to effectively coordinate and integrate the planning and execution of public functions of common interest. The study focused on metropolitan governance, originated from the observation of the gap between governance initiatives and the actions effectively implemented in the context of the state of São Paulo in the period of the creation of the Metropolis Statute, which occurred in 2015. A possible observation space of these issues is the Metropolitan Region of the Vale do Paraiba and Litoral Norte (RMVPLN), located in the Paulista Macrometropolis, in view of its diversity, as well as the large distance between the date of its proposition and that of its institutionalization, meaning a complex context of variables for study. The study investigates how the processes of creation and institutionalization of this Metropolitan Region took place, from institutionalization negotiations to the attempt at consolidating metropolitan governance, seeking to develop the hypothesis that there is a centrality in what is called the regional fact, to the detriment of the metropolitan fact. Based on a descriptive quanti-qualitative research and using data published by research institutions, social media and interviews, the meanings of the creation of the RMVPLN are raised and the governance process is put into perspective in the context of planning on a regional scale.

KEYWORDS: Urban Planning; governance; metropolitan region; Metropolitan Region of Vale do Paraíba e Litoral Norte (RMVPLN); paulista macrometropolis. 


\section{Introdução}

Tendo em vista o aprofundamento da problematização de alguns dos aspectos da governança metropolitana, este artigo foca o estudo do processo da criação e da institucionalização, e a atual situação em que se encontra a Regiâo Metropolitana do Vale do Paraíba e Litoral Norte - RMVPLN, situada na Macrometrópole Paulista - MMP. Para tanto, explora-se descritivamente o desenvolvimento desse processo, na tentativa de abarcar os limites e potencialidades encontrados nas relaçóes entre os atores regionais. Partindo da hipótese da existência de uma lógica particular dentro das açóes do grupo de atores propositores da RM, lógica essa centrada no argumento do fato regional em oposição ao argumento do fato metropolitano, procura-se compreender como se deu a prática dos atores envolvidos diante das condicionalidades históricas expressas na dialética da governança do território metropolitano5.

Metodologicamente, são utilizados para o trabalho de análise sobre a governança da RMVPLN o recurso das entrevistas semiestruturadas ${ }^{6}$ (MARCONI; LAKATOS, 2010), buscando abordar as particularidades da trajetória desde a proposição até a institucionalização da mesma, levantar seus sentidos, significados, dando base para a análise do relacionamento entre os atores, entre governantes e governados, assim como para o resgate das principais questóes que dão sentido à movimentação dos atores e, por fim, para a análise acerca da relação entre a legislação existente e a prática de planejamento regional, dentro do marco teórico definido acima ${ }^{7}$.

\footnotetext{
Essa pesquisa recebeu o Certificado de Apresentação para Apreciação Ética (CAAE), sob o N. 46505115.5.0000.5503

6 Para as entrevistas semiestruturadas, foram selecionados atores diretamente relacionados e protagonistas do processo de formação e institucionalização da RMVPLN, com a ressalva de essa ser uma parte dos sujeitos previstos no cronograma geral de uma pesquisa maior. Os atores entrevistados nessa pesquisa até o momento são: o ex-deputado Carlinhos Almeida, autor do projeto de lei de criação da RMVPLN, o ex-prefeito do município de Jacareí Hamilton Ribeiro e o técnico que assessorou o deputado estadual Carlinhos Almeida na redação e atuou como "secretário executivo" durante as negociações da primeira proposta de Projeto de Lei para criação da RMVPLN, o sociólogo Moacyr Pinto da Silva, além dos professores universitários de duas importantes instituições de ensino e pesquisa da região, professora Sandra Costa, da UNIVAP, e professor José Rogério Lopes, da UNITAU, ambos partícipes dos debates ocorridos durante o momento inicial da RMVPLN.

7 Durante a pesquisa, levantaram-se, por meio dessas entrevistas, informações sobre as questões atinentes à produção e à reprodução social do espaço regional e, portanto, fundamentais nas relações entre os entes federativos atuantes no território, ou seja, aquilo que se concertou chamar Funções de Interesse Comum (FPICs) no contexto da normativa das regiões metropolitanas brasileiras - Estatuto da Metrópole. Não obstante não estarem definidas na norma da própria região metropolitana em questão, as principais inquirições de cunho regional apareceram nas entrevistas, quais sejam: questão ambiental, e/ou da água, referente ao uso compartilhado pelos municípios da bacia do Rio Paraíba do Sul; a questão do saneamento básico intermunicipal; a problemática da mobilidade populacional; e a questão da saúde.
} 
As apresentaçóes do processo acima aludido e do histórico do desenvolvimento regional da RMVPLN em suas diferentes fases, bem como do panorama de dados socioeconômicos, demográficos e de mobilidade, ou deslocamento intrarregional, são realizadas com base em levantamentos bibliográficos de revistas e artigos acadêmicos, publicaçóes dos mandatos dos parlamentares envolvidos no processo, atas de reuniôes, sites das instituiçóes de planejamento do governo estadual, notas técnicas, jornais e revistas da região; além de dados da Fundação Sistema Estadual de Análise de Dados (SEADE), da extinta Empresa Paulista de Planejamento Metropolitano (EMPLASA) e do Instituto Brasileiro de Geografia e Estatística (IBGE).

Partindo da discussão e da metodologia colocadas, apresenta-se, a seguir, além dessa introdução, uma primeira seção sobre o conceito de governança, partindo dos conceitos de fato metropolitano e de fato regional, passando por diferentes visóes sobre governança metropolitana, para chegar aos estudos da governança metropolitana brasileira; em seguida, a descrição da RMVPLN no contexto da Macrometrópole Paulista; posteriormente, uma amostra das informaçóes e das análises levantadas através de entrevistas realizadas e, dentro dos limites colocados, a exposição dos resultados obtidos com a pesquisa, em diálogo com as bases teóricas, retomando-se a hipótese levantada inicialmente.

\section{Limites e potencialidades da governança metropolitana}

O termo governança é utilizado para descrever a natureza e o papel do Estado na sequência de reformas no setor público nas décadas de 1980 e 1990, deixando de atender somente à burocracia hierárquica para atender ao mercado e às redes (BEVIR, 2009). Com o enfraquecimento do Estado anteriormente organizado e o fortalecimento dos atores não estatais, como o empresariado e as Organizaçóes Sociais (OS), surge a preocupação com a capacidade de o próprio Estado coordenar todos esses atores. A crescente participação de atores não estatais sugere dúvidas, principalmente, quanto à democratização da responsabilidade e aos mecanismos para atingi-la. Assim, criam-se estratégias de gestão, regulação e auditorias de organizaçôes para supervisionar a prestação dos serviços. Compreendido isso, portanto, segundo Bevir (2009), governança é a crença amplamente difundida segundo a qual o Estado não pode agir sozinho na resolução de suas intenções e na efetivação de suas políticas.

A metrópole é reconhecida como uma escala superior da urbanização, é multidimensional e ampla, um "fato histórico, social, econômico e cultural, incluindo aí o ambiental” (MARIA; DAVANZO; NEGREIROS, 2010, p. 68). 
Ponto central na hierarquia das estruturas urbanas, a metrópole e sua definição é um tema em debate, sendo uma arena contestada (KLINK, 2010). Ao tratar dessas características que definem as metrópoles, observa-se também, além do aspecto econômico, como a dinâmica regional se aplica nos termos de uma dimensão regional mais ampla. Ainda se soma a essa definição das características da metrópole, ou ao fato metropolitano, a questão demográfica, conforme afirmam Maria, Davanzo e Negreiros, 2010:

A essa dinâmica econômica associa-se a demográfica, evidenciada pela concentraçáo populacional e por elevada densidade, além de uma dinâmica urbana materializada, frequentemente, pela conurbação entre municípios e pelas relações de integração e complementariedade entre núcleo e municípios da área de influência, que resultam em fluxos entre o núcleo e a periferia. (MARIA; DAVANZO; NEGREIROS, 2010, p. 70).

Compreender a visão acima, acerca da definição do que vem a ser a metrópole, e o fato metropolitano, ainda que considerando as limitaçóes da mesma, é importante, pois coloca o debate do planejamento regional mais próximo da escala metropolitana e, ademais, ajuda a compreender a relação entre as características multifuncionais e dinâmicas ampliadas dessa escala e as levadas em conta na sua institucionalização dentro da definição jurídico-normativa brasileira, colocando em questấo o sentido das açôes de planejamento regional.

Nessa particular forma de ver, pode-se ver, por um lado, problemas de adequação entre os territórios metropolitanos e os quadros institucionais estabelecidos para sua gestão e, por outro, a indução de necessidades de cooperação que dificilmente são atendidas por esses processos e seus quadros institucionais. Assim, os autores chegam à conclusão de que decorrem dessa relação boa parte dos problemas relacionados com a questáo dos limites adequados para a regiáo metropolitana institucionalizada e a multiplicidade de atores envolvidos na governança desses territórios, ou seja, constituindo um problema de governança metropolitana (MARIA; DAVANZO; NEGREIROS, 2010).

Contudo, considerando-se, o contexto da globalização e da reestruturação produtiva, englobando processos que resultam em uma reordenação das escalas territoriais, com efeitos desestabilizadores sobre os regimes de governança urbana (BRENNER, 2018) e governança metropolitana (KLINK, 2010), é fundamental o conceito trazido por Lencioni (2017) sobre o que vem a ser o processo de metropolização. Esses processos são caracterizados por profundas alterações socioeconômicas, políticas, tecnológicas e culturais de grande impacto 
na transformação do território, capazes de desafiar a compreensão e o desenho dos limites e potencialidades da governança metropolitana nele inserida, chamados pela autora de metamorfose do espaço metropolitano.

$\mathrm{Na}$ escala regional não é diferente, pois são ainda mais sentidas as transformaçôes em processo sob o território policêntrico, já que as demandas por soluçóes para problemas de alcance regional atingem diretamente os governos locais (FREY, 2007). Ademais, a metamorfose do espaço metropolitano configura-se de uma forma que incide sobre os espaços metropolizados e os não-metropolizados, justamente por estarem sob a égide da globalização e da reestruturação produtiva (LENCIONI, 2017).

A despeito da explicação causal, é notório que a governança metropolitana enfrenta um limite representado pelo mister de pronunciar as pressóes das diferentes vozes locais coabitantes do processo de urbanização planetária (LEFEBVRE, 2008), dentro e no contexto da metamorfose do espaço metropolitano e o que esta representa (LENCIONI, 2017), estando a cada passo exposta às consequências da urbanização extensiva (MONTEMOR, 2006). De modo que, vinculando as duas visóes, a do fato metropolitano e a da contextualizaçáo do processo de metropolizaçáo, impóe-se a questão acerca dos limites e das possibilidades dessa última visão acerca da governança regional metropolitana.

Compreender o significado da disputa pelos espaços estrategicamente posicionados é matéria importante quando se busca os porquês dos atos estatais. Dentro da disputa por hegemonia, existem diferentes lados e o território brasileiro constitui-se de regionalizaçóes que, ao longo do tempo, foram alvo de estudos e teorizaçóes que definiram variadas classificaçóes, desde as que consideram as relaçóes homem-meio, passando pelas que incorporam as características culturais e econômicas, depois as que somam as determinantes do desenvolvimento do capitalismo globalizado, até, por fim, aquelas que consideram importante, também, o olhar decolonial de regionalização, ou seja, uma nova conceitualização que passa a incorporar a "regionalização de baixo para cima" (HAESBAERT, 2020, p. 44).

Ao buscar compreender uma região, é necessário, portanto, observar como se dão as determinantes da reprodução capitalista em cada espaço e as diferenciaçóes expressas, sendo esse processo de reproduçáo capitalista nada mais que as relaçóes sociais e políticas inexoravelmente ligadas ao espaço em questão, conformando o fato regional. "Desta maneira, a regionalização como fato encontra-se vinculada aos jogos dinâmicos da disputa de poder, inscritos nas diferentes formas de apropriação (construção e uso) do território" (RIBEIRO; SANTOS; RODRIGUES, 2015, p. 195). 
O aumento dos débitos internacionais contraídos pelos estados nos anos 1980 e 1990 traz a preocupação com as políticas voltadas para inclusão e justiça social e as instituiçóes políticas, como o Banco Mundial, passam a utilizar o termo Good Governance para elaborar propostas para um "mundo melhor" (WORLD BANK, 1992; FREY, 2008). É notória, ainda que contraditória, a existência de um impasse no debate sobre os contextos, significados e implicaçóes dessas mudanças no Estado e nas óticas de interpretação do processo. $\mathrm{O}$ impasse consiste na existência de posições teórico-ideológicas intransigentes, com argumentos contra ou a favor da governança, que implicam sobre o avanço do debate sobre governança, daí a contradição. Ademais, devido à diversidade de contextos, há certa dificuldade em atingir resultados conclusivos nas comparaçôes entre os casos de governança metropolitana e nas análises sobre governança, na identificação da eficácia, ou não, das soluções de governança adotadas (FERRÃO, 2013; STORPER, 2014).

Há uma narrativa, partindo da transição ocorrida nos países capitalistas centrais, após os anos 1980, que, no contexto de uma profunda reestruturação do Estado, muda de uma "ótica de governo" para uma "ótica de governança” (FERRÃO, 2013, p. 258). A ótica de governo seria aquela vinculada a uma visão hierárquica de comando e controle por parte dos atores públicos; já a ótica de governança seria aquela visão conectada aos processos não hierárquicos de tomada de decisão e de coordenação, com atores públicos e privados. É preciso que se perceba, não obstante, a posição do governo estruturalmente dominante nessa relação (FERRÃO, 2013).

A visão de Rojas, Cuadrado-Roura e Guell (2005) apresenta a governança especificamente metropolitana como uma governança colaborativa, de cooperação entre os entes políticos e sociais de uma regiáo, atuantes em função do planejamento e da gestão, articulados entre as especificidades de cada território e suas necessidades socialmente vivenciadas. Segundo o prisma de Rojas, CuadradoRoura e Guell (2005), a governança regional é a maneira de se antecipar aos entraves comuns às regiôes com grandes concentraçôes urbanas. A criação de regióes metropolitanas, para os autores, portanto, seria uma prática de governança que é afirmada entre entes privados e públicos, colaborativamente, para a oferta de serviços econômicos, sociais e ambientais (ROJAS; CUADRADOROURA; GUELL, 2005).

Uma visão crítica das questôes que envolvem a governança das regiôes metropolitanas afirma que em nenhuma escala existe algo inerentemente colaborativo entre os atores sociais, já que estas são arenas contestadas, em que os atores se movimentam com a finalidade de alcançar diferentes interesses, muitas 
vezes antagônicos; portanto, seria contraditório esperar uma tendência natural nos processos de governança metropolitana e o entrosamento comum dos problemas (KLINK, 2013).

Essa forma de ver a governança na escala das regiões metropolitanas não está em incongruência com a afirmação de que estas são uma escala privilegiada de resolução das questóes urbanas, pois oferecem de fato maiores possibilidades de resolução de desafios do que a governança nas fronteiras municipais. Deste modo, as metrópoles são espaços privilegiados de ação contra as crises cíclicas do capitalismo, ou seja, potencialmente permitem suprir demandas econômicas de determinados setores dominantes da sociedade, a chamada economia política da escala metropolitana (KLINK, 2010, 2013).

A governança metropolitana é, então, a escala de governança por excelência, uma vez que exibem alto nível de interdependência econômica, social, ambiental, infraestrutural e de ordenação pública, contudo, para as quais há raramente uma autoridade política abrangente e unificada (STORPER, 2014).

Construir governança metropolitana, primeiramente, é constituir instituições em uma nova geografia escalar; em segundo lugar, existe o fato de que essa construção precisa ser feita sob um Estado já estruturado, particularmente em relação ao território, ou seja, a política de escala é derivativa de uma política de espaço já dada, política e historicamente definidas (COX, 2010). Portanto, a questão da escala pode ir muito além das disputas entre as cidades e a competição para ver qual delas recebe mais investimento na era liberal, porque a estrutura escalar do espaço metropolitano é a arena em que as forças da competição territorial se dão e essa estrutura é a municipalidade, a nacionalidade e a internacionalidade da metrópole (COX, 2010).

Storper (2014) sugere um ponto inicial para a análise da eficácia da governança metropolitana: a relação governantes-governados, indicando que o uso do solo metropolitano, assim como a provisão de serviços e bens públicos e regulação ambiental, sempre envolverão um descompasso entre governantes e governados. Além do mais, segundo ele, a perspectiva das classes sociais e suas relaçôes com o governo, diante dessas disputas, aponta que quem perde geralmente são os mais fracos, exigindo, assim, uma governança por meio de "bricolagem”, ou uma forma artesanal, para o seu desenvolvimento mais equilibrado (STORPER, 2014).

Os modelos e práticas brasileiras de desenvolvimento metropolitano têm sido bastante investigados (CARNEIRO; FREY, 2018; MARGUTI; COSTA; FAVARÃO, 2018; KLINK; DENALDI, 2015; KLINK, 2010, 2013; FREY, 2004, 2007; MAGALHÁES, 2010; SOUZA, 2007; AZEVEDO; RIBEIRO; 
SANTOS JUNIOR, 2009; CARVALHO, 2009; GARSON, 2009; SANTOS; FERNANDES; TEIXEIRA, 2013; BRESCIANI; SANTOS Jr, 2016; ARAUJO; FERNANDES; COELHO, 2016). As pesquisas demonstram, entre muitas outras coisas, diferentes etapas no processo de fortalecimento dos arranjos institucionais, principalmente nos aspectos legais, que favorecem a governança metropolitana (lei dos consórcios, saneamento ambiental, estatuto da metrópole, etc.); por outro lado, demonstram também a ausência de um padrão de financiamento para a governança das metrópoles a partir de conceitos mais amplos do que a simples disponibilidade de recursos, bem como a fragilidade e, em alguns casos, o esgotamento das estruturas de participação social.

Enfaticamente, existe a questáo da carência de uma autoridade na escala metropolitana, como indica Storper (2014), que se agrava frente à crise do federalismo brasileiro (LEITÃO, 2009), um problema necessariamente ligado ao histórico de desenvolvimento social e econômico do país, calcado na modernização conservadora, oriunda da transição passiva do modelo escravocrata, seus gargalos e contrassensos; bem como aos limites estruturais do estado nacional, patrimonialista e profundamente marcado historicamente pelo capitalismo dependente (MARICATO, 2011; FERNANDES, 2005).

Um princípio básico de política considera que a força de cada ator está relacionada com a sua capacidade mobilizadora e está ligada à estratégia por trás de cada passo dado no jogo político. As disputas de hegemonia são processos em que as expressóes das diferentes táticas usadas pelos atores para atingir suas estratégias se encontram com as dos adversários - e, muitas vezes, com elas mesmas -, impondo as transformaçóes - ou autotransformaçóes - a partir das forças sociais mobilizadas. O esgarçamento das contradiçóes oriundas das disputas políticas faz com que despontem os elementos sociais e políticos atuantes para as transformaçóes ao longo da história (GRAMSCI, 2013; GRUPPI, 1978).

Nos dias atuais, há ainda que acrescentar, diante dos projetos políticos vigentes na atualidade, que, apesar das experiências comunicativas de planejamento e governança regional positivas ao longo do tempo, pouco se abre espaço para concretizar a democratização do país, ou seja, prevalece uma conjuntura conservadora e por vezes fascista na política brasileira, altamente limitante para as necessárias transformaçóes na estrutura social. 


\section{A Macrometrópole Paulista e a Região Metropolitana do Vale do Paraíba e Litoral Norte}

O estado de São Paulo é caracterizado por uma complexa rede metropolitana e conta com seis regióes metropolitanas, Região Metropolitana de São Paulo, Regiáo Metropolitana da Baixada Santista, Região Metropolitana de Campinas, Região Metropolitana do Vale do Paraíba e Litoral Norte, Região Metropolitana de Sorocaba, englobadas na chamada Macrometrópole Paulista (MMP), rede esta que apresenta grandes desafios, tais como os relativos ao saneamento, ao abastecimento de água e à habitação.

Quadro 1 - Caracterização da Macrometrópole Paulista

\begin{tabular}{|c|c|}
\hline $\begin{array}{c}\text { População total (e em } \\
\text { relação ao total do Estado } \\
\text { de São Paulo - 2018) }\end{array}$ & 33 milhões $(74,7 \%)$ \\
\hline $\begin{array}{c}\text { População em relação } \\
\text { ao total do país }\end{array}$ & $16,1 \%$ \\
\hline $\begin{array}{c}\text { Território em relação ao } \\
\text { do Estado de São Paulo } \\
\text { (e dimensão total) }\end{array}$ & $21,5 \%$ (53,4 mil quilômetros quadrados) \\
\hline $\begin{array}{c}\text { Território em relação } \\
\text { ao total do país }\end{array}$ & $0,6 \%$ \\
\hline Municípios & 174 \\
\hline $\begin{array}{c}\text { Distância máxima } \\
\text { da capital }\end{array}$ & Raio de $200 \mathrm{~km}$ \\
\hline $\begin{array}{c}\text { Taxa de urbanização } \\
\text { do território }\end{array}$ & 2,68 milhóes \\
\hline $\begin{array}{c}\text { PIB em relação ao } \\
\text { total do Estado de } \\
\text { São Paulo (2016) }\end{array}$ & $94,83 \%$ \\
\hline $\begin{array}{c}\text { PIB em relação ao } \\
\text { total do país }\end{array}$ & $89,1 \%$ \\
\hline precários & \\
\hline
\end{tabular}




\begin{tabular}{|c|c|}
\hline $\begin{array}{l}\text { Patrimônio natural } \\
\text { em relação ao total do } \\
\text { Estado de São Paulo }\end{array}$ & $20 \%$ \\
\hline $\begin{array}{l}\text { Regióes metropolitanas } \\
\text { componentes }\end{array}$ & $\begin{array}{l}\text { Região Metropolitana de São Paulo, Região } \\
\text { Metropolitana da Baixada Santista, Região } \\
\text { Metropolitana de Campinas, Região } \\
\text { Metropolitana do Vale do Paraíba e Litoral } \\
\text { Norte, Região Metropolitana de Sorocaba. }\end{array}$ \\
\hline $\begin{array}{l}\text { Aglomerações Urbanas } \\
\text { e outras divisões } \\
\text { administrativas }\end{array}$ & $\begin{array}{l}\text { Aglomeração Urbana de Jundiaí, } \\
\text { Aglomeração Urbana de Piracicaba e } \\
\text { Unidade Regional Bragantina. }\end{array}$ \\
\hline
\end{tabular}

Fonte: Emplasa (2019), Pasternak e Bógus (2019).

A urbanização do território da chamada Macrometrópole Paulista se deu em um processo em que o parque industrial concentrado na capital do estado de São Paulo espraia-se para o interior, ação mobilizada pelas políticas de planejamento, configurando um processo desterritorialização das forças produtivas, provocado pelo Estado através de planos e açôes de planejamento (MARIA; DAVANZO; NEGREIROS, 2010; TAVARES, 2018).

A MMP é abordada como "Macrometrópole" pelo sociólogo Vilmar Faria em 1981, que fez o uso do termo pela primeira vez, com base na teoria das cidades hierarquizadas (TAVARES, 2018). Posteriormente, Lencioni (2003, 2004) estudou a MMP a partir da visão de "cidade-região global", em que distingue a MMP da chamada megalópole.

A RMVPLN localiza-se na MMP, no leste do Estado de São Paulo, e é formada por 39 municípios, distribuídos em cinco Regiōes de Governo: São José dos Campos, Taubaté, Caraguatatuba, Guaratinguetá e Cruzeiro, que ocupam área de 16.268 quilômetros quadrados, o que significa 6,5\% do território paulista. Tem sua formação primeira no século XVI, quando se dá o transbordamento das movimentaçôes populacionais na região litorânea, momento em que se dá o povoamento das áreas onde hoje se encontram os municípios de São Sebastião e Ubatuba. Ainda na fase inicial, porém, no século XVII, há o estabelecimento de uma aglomeração, com características de vila, na região próxima à calha do rio Paraíba do Sul e na localidade onde hoje se encontra o município de Taubaté; nesse local se forma o principal núcleo, marcado como o ponto de onde partem e chegam empreitadas à busca de metais, bem como se dá a comercializaçáo da força de trabalho indígena para os canaviais litorâneos (RIBEIRO-MOREIRA; MELLO, 2010). 
A cafeicultura é o elemento fundamental da economia na região do Vale do Paraíba, principalmente no século XIX, já que a riqueza gerada da produção cafeeira promove crescimento e diversificação das funçôes dos centros urbanos. Numerosas fazendas dedicam-se à monocultura do café nas abundantes terras virgens do vale do rio Paraíba que, somadas ao clima favorável, propiciam alta produtividade por quase um século (MULLER, 1969). Posteriormente, é também importante, no final do século XIX, a chamada fase industrial e, como em outras localidades, as manufaturas foram favorecidas pela força de trabalho advinda da cafeicultura, pela acumulação de capital proveniente dos períodos precedentes. Soma-se a isso o fato de se localizar entre o Rio de Janeiro e São Paulo, importantes centros econômicos do país, assim como a presença da ferrovia, para a evolução da produção de bens industrializados na região do Vale do Paraíba (RIBEIRO-MOREIRA; MELLO, 2010).

O referido ciclo veio a acontecer nas sub-regióes do Vale do Paraíba onde houve o desdobramento de um crescimento econômico anterior e, com isso, a região da Calha do Vale, também conhecida como "Vale Médio", tem desenvolvimento nesse processo, diferentemente das demais regióes, que ficam dependentes desta. Como destacam Ribeiro-Moreira e Mello:

Eram, assim, reforçadas as desigualdades inter-regionais, características da ordem capitalista, onde as zonas mais desenvolvidas tendem a atrair, progressivamente, mais investimentos, enquanto outras, de menor vigor, tendem ao prejuízo (RIBEIRO-MOREIRA; MELO, 2010, p. 8).

A chamada política nacional de substituição de importações e, ao mesmo tempo, a política nacional de desenvolvimento vão rebater no Vale do Paraíba e, nessa conjuntura, durante a década de 1950 do século XX, há o advento da Siderúrgica Nacional, em Volta Redonda, além da inserção da Rodovia Presidente Dutra. A inauguração da Rodovia planteia um marco na urbanização regional, já que agencia a atração de indústrias e de investimentos em diversos setores, de maneira particular da indústria que se beneficia do eixo entre as duas maiores cidades do país, para a realização integral do ciclo econômico da mais-valia capitalista: produção, circulação e venda de mercadorias (VIEIRA; SANTOS, 2012).

A história da RMVPLN passa por transformaçôes significativas nos anos recentes, recebe investimentos industriais, assim como do setor imobiliário, sendo que os setores industriais e de serviços se destacam na composição econômica (SÃO PAULO, 2013). Além disso, a atividade extrativa também ganha 
importância com a produção de minerais não-metálicos, areia, por exemplo, incidindo nas cidades de Tremembé, Taubaté e Jacareí. Sobressaem-se, também, na indústria de transformação, a aeronáutica e a aeroespacial, representando 9,1\% dos vínculos empregatícios regionais (SÃO PAULO, 2013), além das que se referem a material de transporte, montadoras e autopeças, com importante posto na regiáo. No que diz respeito ao Produto Interno Bruto (PIB), o Valor Agregado (VA) do setor industrial representa 37,5\% do total em 2014 (SEADE, 2014).

Resumidamente, o setor de serviços é o maior gerador de empregos, sendo responsável por mais de $35 \%$ das vagas existentes na região, seguido pela indústria, com 24\%. No PIB, o VA do setor de serviços representava $61,9 \%$ do total em 2014 (SEADE, 2014). A agropecuária representava uma pequena participação no VA da RMVPLN, de 0,5\% em 2014, sendo que fora de 0,9\% em 2002, apresentando, portanto, queda.

Os municípios de São José dos Campos, Taubaté e Jacareí agrupavam $75,8 \%$ do PIB da região em 2002 e 63,8\% em 2014. Taubaté exibia PIB de 13,9\% do total da região em 2002 e em 2014 chegava com 15,9\%, com alta. São José dos Campos representava 45,2\% do total do PIB da RMVPLN em 2002 e, com queda, vai a $31,8 \%$ em $2014^{8}$.

As qualidades populacionais da RMVPLN são heterogêneas, pois observa-se haver um elevado grau de urbanização e concentração populacional no Litoral Norte e no eixo da Rodovia Presidente Dutra e um baixo grau de urbanização e concentração populacional no Alto do Paraíba. Os municípios mais urbanizados são: Campos do Jordão (99,4\%), seguido de Ilhabela (99,3\%) e São Sebastião $(98,9 \%)$; os menos urbanizados são: Paraibuna (30,1), Natividade da Serra $(41,7 \%)$ e Monteiro Lobato (43,1\%) (CUNHA; SILVA; BECCENERI, 2019).

\section{A criação e a institucionalização da RMVPLN}

A RMVPLN é criada pela Lei Complementar no 1.166, de 09 de janeiro de 2012, segundo a qual estão juntos 39 municípios. Proposta com o objetivo de abranger os mais diversos atores políticos e sociais em um processo político de caráter regional, a iniciativa parte do mandato legislativo do então deputado estadual Carlinhos Almeida, do Partido dos Trabalhadores 9 . Apresentada em forma de Projeto de Lei Complementar à Assembleia Legislativa em 2001, a pro-

\footnotetext{
8 Essa queda se refere, entre outros fatores, à queda da arrecadação de ICMS, que se dá por meio do repasse feito pelo Governo do Estado de São Paulo (SÃO JOSÉ DOS CAMPOS, 2017).

9 Prefeito de São José dos Campos entre os anos de 2013 e 2016.
} 
posta é discutida com governos municipais, partidos, universidades, sindicatos, empresários e cidadãos (CÂNDIDO, 2010; VALE, 2012).

Destacadamente contestada, a ideia de criar uma Região Metropolitana (RM) consegue aderências, mas, principalmente, resistências. Como é possível averiguar na matéria de Lima (2011) e nas entrevistas realizadas, as divergências foram assinaladas por diferentes agentes, tanto de gestores como da sociedade civil, inclusive pesquisadores de universidades, mas especialmente técnicos e assessores do governo do estado, sustentados em argumentos que dizem respeito à ausência do chamado fato metropolitano.

A análise das entrevistas mostra que, ao apresentar e pôr em discussão a proposição da RMVPLN, seu autor teve a intenção de provocar um processo ativo de planejamento regional, de que a criação da RM fosse entendida como um resultado do sucesso de um amplo envolvimento político dos atores regionais nos temas que os atingem diretamente de maneira comum, mobilizando os atores em torno dos seus desafios e potencialidades.

Na primeira fase do processo de criação da RMVPLN, o Governo do Estado objetou frontalmente o projeto de apresentado pelo entáo deputado Carlinhos Almeida e, em contraposição, defendeu a criação de uma aglomeração urbana entre os municípios da chamada "Calha do Vale" (de Jacareí a Guaratinguetá) $^{10}$, e três microrregiôes (Mantiqueira, Litoral Norte e Vale Histórico). Assim como o Governo do Estado, os prefeitos dos dois maiores municípios envolvidos, São José dos Campos e Taubaté, também deixaram de participar do processo de debates conduzidos pelo autor da proposta e demonstraram ser contra a mesma.

A versão e o processo de discussão contidos no projeto original de RMVPLN, de 2001, apresentado à Assembleia Legislativa de São Paulo pelo deputado Carlinhos Almeida, não prosperou. Ela volta a ser colocada, no ano de 2007, por uma frente pluripartidária de deputados (CÂNDIDO, 2010). Dessa vez não há a disposição de colocar a RMVPLN em discussão com a sociedade em geral e formar um processo de debates, conforme depoimentos colhidos junto a alguns dos entrevistados, substituindo-a pela direta busca de conciliação com o governo do estado. Em 2012, um terceiro Projeto de Lei Complementar, autorizando a criação da RMVPLN, dessa feita de autoria do próprio Governo do Estado, é aprovado pela Assembleia Legislativa, passando o executivo estadual a cuidar da sua implantação.

\footnotetext{
${ }^{10}$ Conforme o uso e a definição de Calha do Vale encontrados em Ribeiro-Moreira e Mello (2010).
} 
É possível afirmar que, após quase 10 anos de aprovação da institucionalização da RMVPLN, as atividades desenvolvidas nessa escala de governança se resumiram à criação do FUNDOVALE, previsto na lei, com valores suficientes para a criação do mesmo e de alguns decretos protocolares relativos às açôes de mobilidade, decorrentes das exigências legislativas a serem cumpridas. Ademais, foram realizadas reuniôes entre os componentes do Conselho de Desenvolvimento da RMVPLN, no âmbito do qual se deram tratativas para a elaboração do Plano de Desenvolvimento Urbano Integrado - PDUI, previsto nas normas do Estatuto da Metrópole, processo esse que se encontra, conforme informado em entrevista, dentro de um impasse financeiro e político-administrativo.

Além das iniciativas citadas no parágrafo anterior, em 2015 foi criada a Agência de Desenvolvimento da Região Metropolitana do Vale do Paraíba e Litoral Norte (AGEMVALE), estrutura do Governo do Estado para a articulação dos interesses dos entes regionais. Essa instituição, por ser uma autarquia, deu agilidade aos processos burocráticos, antes concentrados nos entes da Secretaria de Estado e submetidos às dinâmicas de reuniôes do Conselho de Desenvolvimento; no entanto, a falta de uma prática de governança regional metropolitana que envolva os entes públicos e privados, além da falta de uma autoridade que faça a mediação entre os recursos disponíveis e os entes da federação envolvidos, impóem-se sobre a RMVPLN na consolidação das açóes de planejamento regional.

\section{Planejamento e governança regional na RMVPLN}

Bem antes das primeiras iniciativas no sentido de formalizar a implantação da RMVPLN, já haviam sido feitas diversas tentativas de impulsionar o planejamento na mesma (GOMES; RESCHILIAN; UEHARA, 2018). Como forma de sintetizar os sentidos buscados nessas açóes, buscamos associar as informações das entrevistas realizadas até o presente momento na pesquisa, retomando historicamente esse processo até o momento da institucionalização da mesma, dando ênfase ao fato regional, principal sentido identificado na proposição da sua institucionalização, em contraposição ao fato metropolitano.

Doravante, no balanço negativo das limitaçóes e dos desafios encontrados pelo caminho, as falas destacadas demonstram claramente como é fundamental a compreensão dos papéis dos atores no processo de criação da RMVPLN, principalmente por suas vinculaçóes políticas serem oriundas de uma práxis contra hegemônica de planejamento regional. Assim, ao ouvir seus pontos de vistas e 
relacionar com sua trajetória, analisa-se como a posição assumida politicamente nas falas é fundamental para compor uma visão crítica acerca dos significados das suas atitudes, táticas e estratégicas, nas relações com os demais atores e com o contexto vivenciado na regiáo.

A iniciativa que melhor delimita o planejamento da região na perspectiva da governança foi a criação, em 1970, do Consórcio de Desenvolvimento Integrado do Vale do Paraíba (CODIVAP), criado com o objetivo de buscar caminhos para a superação dos problemas comuns entre os municípios consorciados, aproximando-os politicamente, na perspectiva de promover um crescimento harmonioso entre os municípios da regiáo. O CODIVAP teve como primeiro superintendente o ex-ministro da Indústria e Comércio do Governo Emílio Garrastazu Médici, Paulo Egydio Martins, que deixou o cargo para assumir o governo paulista. Essa relação política evidencia a vinculação dos interesses locais com os nacionais e estaduais, em um período de forte centralização política, administrativa e econômica no país, mesmo que, na apresentação do relatório de caracterização da região, o superintendente ratifique a importância do consórcio para a descentralização administrativa (VIEIRA; SANTOS, 2012).

Perante a conjuntura de debates, o papel do CODIVAP e as açóes e planos estatais focados na região do Vale do Paraíba e Litoral Norte são abordados de forma destacada por um dos atores entrevistados na pesquisa, conforme segue:

[...] uma crítica que todos os prefeitos quase que historicamente, quando viram prefeitos, com o tempo começam a fazer em relação ao consórcio, que é o CODIVAP: "Ah, que o CODIVAP não é, é que é um clube de amigos", porque não consegue ter resolutividade, não consegue atacar os problemas conjuntamente, não se consorciam entre alguns municípios para ver. O que que gerou do CODIVAP até hoje que conheci, foi muito pontual aqui na região nossa, no caso de Jacareí, foi o consórcio Três Rios que era para cuidar de manutenção de estradas rurais em parceria com dois ou três municípios. (MOTA, 2019).

Diante da proposição de criação da RMVPLN, há a questão da sobreposição das instituiçóes de planejamento e suas implicaçóes, sendo que os atores se posicionam claramente de forma a delimitar o papel do CODIVAP, cada um à sua maneira, conforme segue:

Existiam alguns prefeitos que perguntavam assim: "mas e o CODIVAP? E o Consórcio? ” Porque existia uma possibilidade de você ter uma con- 
traposição entre o Consórcio, as Prefeituras e a Regiáo Metropolitana. E a gente sempre deixou claro o seguinte: a Região Metropolitana é um instrumento de gestáo que deve envolver os Municípios e o Estado, fundamentalmente, mas também a sociedade civil, para a construção de propostas efetivas, inclusive com recursos. Porque uma coisa que a gente previu no projeto foi a criação do fundo e a criação da Agência, de um organismo, para tocar esses projetos, para não ser simplesmente um encontro de boas intenções e boas ideias. Para que os projetos pudessem ser definidos, priorizados e tocados, como faz a EMPLASA em São Paulo, por exemplo. E aí a maioria deles concordou com a ideia, os que tinham essa preocupação. E eu até falava: olha, o CODIVAP não vai perder e até pode fortalecer o seu papel, porque ele vai ser um articulador dos municípios, para que os municípios possam atuar em sintonia, num conjunto, no conselho da Regiāo Metropolitana. (ALMEIDA, 2019).

A posição acima demonstra como a criação e a instituição da RMVPLN surge, originalmente, com o propósito de envolver os mais diversos atores políticos e sociais da regiáo no processo, a partir do impulso advindo do mandato legislativo do então deputado estadual Carlinhos Almeida, do Partido dos Trabalhadores. A proposta é, então, matéria de discussão com governos municipais, partidos, universidades, sindicatos e empresários, conforme dito na fala do deputado acima, com intenção de unir esses atores de maneira a movimentar o planejamento regional.

Ademais, é a partir do exemplo da implantação da Região Metropolitana de Campinas e das articulaçóes no ABC paulista e em Santos que se dá o estímulo para o empenho na criação da RMVPLN, cada uma a seu modo, e em conformidade com a sua realidade política e social. Além disso, o contexto nacional das políticas urbanas, diferentemente dos períodos anteriores, permite que se abra a discussão de outras regióes metropolitanas e, no caso do estado de São Paulo, Campinas faz esse movimento com sucesso, a despeito de não haver ainda legislação especifica para essa escala de governança. A alusão a esses processos pode ser cotejada com as falas dos sujeitos envolvidos na formulação do projeto:

Pesquisei e vi o seguinte, a regiáo de Campinas havia feito uma luta muito forte pela criação da região metropolitana de Campinas. [...] Com a Constituinte Federal e depois Estadual, isso foi regulamentado não tanto com aquela visão, com uma visão um pouco diferente do que tinha no regime militar, de articulação regional mesmo, então, não tanto uma coisa 
de cima pra baixo, mas uma visão de baixo para cima. [...] E isso permitiu que se abrisse a discussão de outras regiốes metropolitanas no nosso caso aqui, no estado de São Paulo, e Campinas fez esse movimento e conseguiu. Diferente de São Paulo que foi uma decisão do governo federal de criar uma região metropolitana, foi um movimento da sociedade e das lideranças políticas, prefeitos, deputados dali da região, que conseguiu. [...] aí eu falei: porque que nós não podemos fazer isso na região do Vale? A partir daí que nós começamos a fazer os estudos e as conversas, levando em conta as semelhanças e as diferenças das duas regióes, que acho que são até maiores do que as semelhanças. (ALMEIDA, 2019).

Considerada polêmica pelo fato de não aderir à tradicional concepção de fato metropolitano, a ideia em si obteve a adesão de alguns atores sociais e oposição de outros. Os desacordos com a proposta foram apontados por alguns estudiosos da temática, principalmente pelas características heterogêneas da região, que caracterizava densidade populacional e pontos de conurbação dispersos (LIMA, 2011). No mesmo contexto de debates, o argumento a favor da criação da RM vem, destarte, com atores que defendem a perspectiva de criar um instrumento de planejamento para deliberar coletivamente sobre uma situaçáo nítida de adensamento urbano em vias de crescimento, vindo a atuar durante esse processo e não após sua instalação e agravamento dos problemas já apontados, destacadamente focado no fato regional.

O imperativo da implementação dessa esfera de governança está nítido nas falas dos atores quando abordam, entre outros temas, a demanda por planejamento regional integrado entre os municípios, conforme se vê nas falas a seguir:

Porque o governo do estado, através da EMPLASA, principalmente, desde o início tinha uma posição muito crítica ao projeto. [...] eles não queriam criar outras regióes metropolitanas. $\mathrm{O}$ governo não queria, não tanto a EMPLASA, acho que mais o governo não queria criar. $\mathrm{E}$ a EMPLASA, ela inventava um argumento técnico, que era o seguinte: que a região do Vale do Paraíba, diferente da regiáo de Campinas, e de São Paulo nem se fale, não era uma aglomeração urbana na sua totalidade. Ou seja, você tinha aglomeraçôes urbanas dentro do Vale. São José, Jacareí e Caçapava é uma, Taubaté, Tremembé e Pinda caminhava para ser outra, e, ali em torno de Aparecida também você tinha uma aglomeração urbana. No litoral, também caminhava para isso. Então, eles diziam o seguinte: que não era uma aglomeração urbana. 
E nós discutimos muito com eles, que, como a partir da constituiçáa de 88, e até de uma lei da constituição de São Paulo e de uma lei estadual que regulamentou as Regióes Metropolitanas, as regióes metropolitanas não podiam ser vistas como eram vistas na época do governo militar, como uma forma de criar um instrumento para resolver uma situação já instalada de aglomeração, mas deveria ser vista como instrumento de planejamento para trabalhar regiôes que estavam em processo de (Eu: De metropolização). Exatamente. [...] então, nós continuamos fazendo debate, movimento, em torno da ideia, mas o governo resistiu muito e não aceitou de maneira nenhuma que o projeto andasse. (ALMEIDA, 2019).

O Governo do Estado, como é possível notar nas falas dos entrevistados, em que discordam da proposta, apresenta como alternativa a criação de um aglomerado urbano, entre os municípios da denominada "Calha do Vale" e três microrregióes (Mantiqueira, Litoral Norte e Vale Histórico). A argumentação da EMPLASA se fundamenta em aspectos técnicos relacionados ao tecido urbano da regiáo, fragmentado e pouco homogêneo, mas o Governo do Estado apresenta posicionamentos políticos bem claros de autodefesa, conforme se vê a seguir, do ponto de vista do assessor e sociólogo Moacyr Pinto:

Eu era secretário executivo desse processo de discussão representando o Carlinhos, [...]. Então aí, desde o início nós tentamos incluir o governo do estado nesse processo e começaram as discussóes propriamente ditas, aí o governo mandou uma pessoa, é, um representante, era uma pessoa muito qualificada, ele era Doutor, o Maurício Hoffman, da Secretaria de planejamento [...]. Ele veio para essa, também desse ponto de vista o estado, vamos dizer assim, valorizou, mas claramente [...] não tinha interesse. Mas, conforme o processo foi avançando, o interesse foi aumentando, ainda que não fosse grande, náo fosse de massa, com uma tradiçáo de não participação, as prefeituras estavam acostumadas com a relaçáo com o governo do estado do "pires na mão", pela relação do "cabresto", esse processo era assim, era libertador, a ideia era criar um caminho de libertação, de uma outra dinâmica [...], então, aí eles dizem não, não estão interessados. Aí, quando começou, e esse fator poderia prejudicar os interesses políticos do governador [pois] ele queria ser candidato à reeleição, [...] eles começaram a fazer, eles saíram do conforto de ficar sentando em cima. Aí ele fica fazendo aquele discurso mais agressivo, negando e falando que não tinha 
[como]. E entáo, eles vieram primeiro com um discurso: não, nós fizemos os estudos, etc., e aqui oh, não cabe região metropolitana, cabe um outro, uma outra conformaçáo de organização da regional. Eles fizeram uma proposta e essa proposta nos ajudou muito porque ela era muito fraca, uma proposta de criar aqui na Calha do Vale que chama, mais ou menos de Guararema, Jacareí, até lá em Cruzeiro, na região de Guaratinguetá, criar um ente, uma escala intermediária, uma Aglomeração Urbana. E criar da Mantiqueira, no litoral, e no chamado Vale Histórico, uma outra, um outro ente. Aí ele nos fortaleceu, até porque era tão bizarra essa proposta, era matar as pequenas, as sub-regiōes, nessas regiôes menores, era colocar, deixar naquela condição mais isolada ainda e sem massa crítica, sem nenhuma condição de se articular, subir regionalmente para se desenvolver. [...] eles não viram sentido, viram necessidade de reagir [...] E aí tem a questão deles de falar que era assim, [...] "Quem é legítimo para propor uma coisa dessa? ” (SILVA, 2020).

Instalado o impasse entre a proposta original do parlamentar e a defendida pelo executivo estadual, o Projeto de Lei Complementar (PLC) foi arquivado, voltando a ser apresentado em 2007, agora assinado por uma frente de deputados eleitos e com interesses políticos na região ${ }^{11}$. Diferentemente da disposição inicial de colocar a RMVPLN em discussão com a sociedade em geral, dessa vez as investidas dos proponentes foram no sentido de conciliação com o governo do estado, que apresentou, por sua vez, o PLC à Assembleia Legislativa (CÂNDIDO, 2010). Em 2012 foi aprovado, então, o Projeto de Lei autorizando a criação da RMVPLN.

As reunióes do Conselho de Desenvolvimento Regional, que se institui quando da criação da RMVPLN, em 2012, acontecem periodicamente e, em suas atas ${ }^{12}$, é possível apurar o levantamento de questóes diversificadas sobre o desenvolvimento regional, com ênfase na necessidade de viabilização de recursos para o Fundo Vale. A criação dessas estruturas administrativas não tem demonstrado, contudo, ser suficiente para movimentar a gestão em torno da elaboração

\footnotetext{
${ }^{11}$ Sabe-se, por meio das entrevistas e dos documentos levantados, que o Projeto de Lei Complementar (PLC) é arquivado e há um segundo momento de propositura do Projeto de Lei Complementar, criando a RMVPL como resultado de um processo de articulação entre os deputados da região, quais sejam: o autor do PLC, Carlinhos Almeida, do Partido dos Trabalhadores, o deputado do Partido Verde Afonso Lobato, o deputado do Partido Progressista Mouzart Russomano, e o deputado Aloísio Vieira, do Partido Trabalhista Brasileiro, em torno das pautas da região.

${ }_{12}$ As referidas atas estão disponíveis no site da AGEMVALE: https://www.saopaulo.sp.gov.br/orgaos-e-entidades/ autarquias/agemvale/. Acesso em: 28 jan. 2022.
} 
do Plano Diretor Urbano Integrado (PDUI), previsto no Estatuto da Metrópole como um instrumento de planejamento regional e de articulação das açóes do governo do estado na Região e dos demais entes federativos, entre eles os governos e entes municipais voltados para as demandas em torno das Funções Públicas de Interesse Comum (FPICs).

Recentemente, no ano de 2018, dá-se início ao processo de elaboração de um termo de referência para a contratação de uma empresa que desenvolva o PDUI, dentro da Diretoria Executiva da AGEMVALE. Entretanto, conforme tem sido possível apurar, através das informaçóes publicadas pela mídia e das entrevistas realizadas, o problema principal advém da falta de recursos para sua manutenção, bem como das alterações na estrutura administrativa da Secretaria de Planejamento Metropolitano, que passa a ser o único órgão com essa função no estado de São Paulo, desde a extinção, em 2018, da EMPLASA.

A norma presente no Estatuto da Metrópole, anteriormente dada, exigia prazo máximo para a apresentação do PDUI e, após a mudança na norma feita pelo governo federal, em 2017, a discussão sobre o PDUI da RMVPLN continua apresentando uma série de impasses. Mais do que apenas limitar a execução do PDUI, esses impasses de 1) ordem financeira (falta de recursos) ${ }^{13}, 2$ ) ordem político-administrativa (gestão), e 3) questôes político-ideológicas, relacionadas à visão do atual governo sobre o papel do Estado, impedem a consolidação de um planejamento voltado ao fato regional ${ }^{14}$.

A questão da gestão dos recursos do FUNDO e o impasse para o acesso aos mesmos, que impossibilita o início do processo de licitação para a elaboração do PDUI, têm impedido o avanço das discussóes que lhe são atinentes. Isto inviabiliza o planejamento regional, de interesse, por exemplo, dos prefeitos dos pequenos municípios, que possuem as maiores urgências e carências, e por sua óbvia maior dependência em relação aos recursos provenientes do estado. Estes acabam sem desenvolver capacidade, sem autonomia para tomar iniciativa. Outro fator importante, no que se refere à participação dos prefeitos da maioria dos municípios nos debates relativos à gestão regional, que vem se somar aos já citados, é a própria dificuldade de compreensão dos mesmos em relação aos

\footnotetext{
${ }^{13}$ A problemática financeira ocorre devido à falta de recursos suficientes para a contratação da consultoria, ou instituição, designada para executar o processo de elaboração do PDUI, orçado em um montante de aproximadamente 4 milhões de reais. Notícias recentes apontam para a permanente diminuição no orçamento da AGEMVALE nos dois últimos anos. Em 2018, o orçamento total foi de 2,54 mi e em 2019 de 1,9 mi, contando os gastos com pessoal e despesas correntes. Manchetes do Jornal O Vale: "Estado reduz em $20 \%$ orçamento para obras e projetos da RMVale", 07/10/2017; "Orçamento RMVale é só 31\% do previsto pela AGEMVALE para 2019", "Promessa desde 2015, PDUI é foco do novo comando da Agemvale", 11/05/2019; "PDUI sai do papel até julho de 2020", 25/07/2019; "Promessa desde 2015, PDUI é foco do novo comando da Agemvale", 18/08/2021.
}

${ }^{14}$ Atualmente, 2021, do governador João Dória Jr., do Partido Social Democrata Brasileiro. 
assuntos relacionados ao planejamento regional; tal deficiência ficou registrada em alguns dos depoimentos das pessoas entrevistadas.

Por fim, ao observar a problemática da governança regional na RMVPLN e ausência de uma iniciativa para estimular a consolidação da mesma no Estado, questiona-se se há real interesse do Governo nessa matéria:

Eu acho assim, uma das coisas que enfraquece a região metropolitana é muito mais a responsabilidade do estado do que dos municípios, porque o seguinte: se o estado estabelece que vai fazer um investimento na regiáo a partir do debate da regiáo metropolitana, eu forço os Prefeitos a levar o seu debate para dentro da RM, por que não tem por onde escapar, agora, quando eu tenho um governo do estado que não estimula, não dá força à unidade dos prefeitos, eu atendo ele individualmente... Vamos pensar de novo. Por que que eu vou gastar minha energia discutindo o rio Paraíba em toda sua extensão se eu consigo ser atendido pelo Governador para construir aquela escola que eu tô precisando? [...] até porque eu penso localmente, eu penso como política de governo e não de estado, penso na minha reeleiçâo, ou seja, qual que é a cabeça do prefeito na ótica de resolver os seus problemas? [...] então, o único que tem força para dizer para o prefeito, olha eu discuto com você a discussão da escola, não tem nenhum problema, mas eu quero isso passando por dentro da regiáo metropolitana. [...] você fazer todo mundo passar a ter o hábito de discussão regional, só que se estimula exatamente o contrário, o nosso presidencialismo de coalizão é fazer o seguinte: eu estabeleço forças pontuais para eu ter poder, que isso numa lógica política o governador pensa assim, eu preciso de apoio dos prefeitos eu atendo o prefeito na sua casa, preciso do apoio da Assembleia, do deputado. Deputado, qual que é a sua base eleitoral? [...] E ninguém nunca discute onde que o calo está apertando lá na Região! [...], enquanto tiver essa lógica de tratamento a regiáo metropolitana do Vale do Paraíba infelizmente caminha para não sair do lugar, virar uma coisa que infelizmente pode se tornar um segundo Codivap, ou seja, existe, mas ele não é um espaço que debate, que discute, que prioriza as questóes mais comuns entre nós, como citei aqui a saúde, a segurança, e quais foram os temas, Saúde, segurança e meio ambiente, desenvolvimento econômico. (MOTA, 2019).

Por fim, combinado a esse problema provocado pelo fim da EMPLASA, manifesta-se a problemática da visão do governo do Estado sobre o seu papel na 
condução da "coisa pública". Pode-se ver, por meio de discursos em aparições públicas do próprio Governador, de seus Secretários, assim como por meio de atos, decretos e projetos de lei enviados à Assembleia Legislativa, e até mesmo aludida em ata do Conselho de Desenvolvimento, a franca defesa da "redução do Estado", a defesa de "ajustes" no orçamento e nos gastos, a orientação por "aumento no potencial de investimento" e também pelo estabelecimento de "parcerias público-privadas" e "concessôes", ponto de vista claramente disjuntivo do que viria a ser uma prática de planejamento regional, como a que foi preconizada no projeto inicial que propôs a criação da RMVPLN ${ }^{15}$.

\section{Considerações Finais}

Uma leitura processual do contexto institucional proporcionada pelas entrevistas realizadas, associada à análise de conteúdo dos dados qualitativos, deu conta de desenvolver a hipótese de estarmos diante de uma regiáo metropolitana que foi fundada na lógica do fato regional, e foi possível notar que o impulso inicial para a proposição da RMVPLN se liga à necessidade de ampliar a capacidade de integrar açôes de cunho regional, atendendo, portanto, demandas de interesse de governança regional metropolitana.

Como colocado na seção introdutória desse artigo, busca-se aqui a compreensão do processo histórico de criação da RMVPLN e, diante disso, tornar possível o breve desenvolvimento da hipótese da existência de uma lógica particular dentro das açóes de governança do grupo de atores propositores da RMVPLN. A ação desse grupo estaria situada na proposta de uma governança fundamentada em processos de planejamento territorial voltados a atender de maneira eficaz as principais demandas dos diversos atores dessa escala regional, com as questóes, por exemplo, ambientais e de saúde, envolvendo politicamente os cidadãos, grupos e entidades da esfera pública e privada.

Os elementos da governança da RMVPLN analisados até o momento, quando relacionados com o contexto de planejamento regional presente, demonstram ser um processo com profundos impasses de natureza político-

\footnotetext{
${ }^{15}$ Para acrescentar existe a crise do coronavírus na RMVPLN, demonstrada em documentos publicados, especialmente a Nota Técnica (NT) sobre a situação da disseminação e contágio do COVID-19, lançada ainda em maio de 2020 pelo Laboratório de Investigações em Sistemas Sócio Ambientais do Instituto Pesquisas Espaciais (LiSS/ INPE) e alguns dados do "Plano de Retomada" publicado em 25 de maio de 2020 pelo governo do estado. Nesses documentos verificou-se a tentativa de avanço na promoção de uma integração regional dos municípios destacadamente limítrofes, como São José dos Campos e Jacareí, e encontrou-se discursos descompassados, ou seja, os municípios, ainda que pertencentes a mesma RM e limítrofes, não consideram em seus planos de ação a governança da situação da saúde uma problemática a se tratar em conjunto e pior, há uma realidade de negligência por parte do governo do estado de São Paulo, um vácuo institucional.
} 
-administrativa e, também, político-ideológica, que implicam o esvaziamento das açóes da recém-instituída RM, diante das açóes disjuntivas do governo do estado de Sáo Paulo.

A superação de tais limitaçôes, além de depender do interesse dos atores envolvidos na sua resolução, requer ainda mais o aprofundamento nas questôes da governança em si, já que, apesar de estar sob a égide do capitalismo neoliberal, o contexto particular em que se inserem as regiôes metropolitanas, conforme sugerido por Storper (2014), é diverso e requer um olhar enviesado, principalmente no que concerne aos países do Sul Global, em suas particularidades históricas (WATSON, 2009).

Retoma-se: o contexto em que se inserem as regiôes metropolitanas brasileiras, qual seja, o da globalização e da reestruturação produtiva, chamado de metropolização por Lencioni (2017), impóe desafios e potencialidades aos processos de governança regional metropolitana. Assim, a existência ou não do fato metropolitano precisa ser cotejada com a forma como se dá a metamorfose do espaço da metrópole nos dias atuais, como teorizado por Henri Lefebvre: homogeneizada, profundamente fragmentada, ao mesmo tempo que muda a hierarquia entre os lugares (LENCIONI, 2017).

\section{REFERÊNCIAS}

AZEVEDO, S.; RIBEIRO, L. C. Q.; SANTOS JÚNIOR, O. A. Metrópoles, cultura política e cidadania no Brasil. Cadernos Metrópole, São Paulo, v. 11, n. 22, p. 347366, jul./dez. 2009.

ALMEIDA, C. [Entrevista concedida ao autor]. São José dos Campos, 23 de agosto de 2019.

ARAújo, S. M. V. G. de; FERnANDeS, A. S. A.; COElHO, D. B. Does Metropolitan Area Management Matter in Brazil?. The Planning Review, Bingley, v.52, n.2, p.17-25, 2016.

BEVIR, M. Introduction In: BEVIR, M. Key concepts in governance. London: Thousand Oaks: SAGE, 2009. p. 3-30.

BRENNER, N. Espaços da urbanizaçáo: o urbano a partir da teoria crítica. Rio de Janeiro: Letra Capital; Observatório das Metrópoles, 2018.

BRESCIANI, L. P.; SANTOS JR., D. A dinâmica da inovação na região metropolitana de Campinas. Revista Brasileira de Gestáo e Desenvolvimento Regional, Taubaté, v. 12, n. 1, p. 410-437, jan/abr. 2016. 
CÂNDIDO, L. R. Informativo da Frente Parlamentar em Apoio aos Municípios do Vale do Paraíba, Litoral Norte e Serra da Mantiqueira. São Paulo, jun. 2010.

CARNEIRO, J. M. B.; FREY, K. (org.). Governança Multinível e Desenvolvimento Regional Sustentável: Experiências do Brasil e da Alemanha. São Paulo: Oficina Municipal, 2018.

CARVALHO, N. R. Geografia política das eleiçôes congressuais: a dinâmica de representação das áreas urbanas e metropolitanas no Brasil. Cadernos Metrópole, São Paulo, v. 11, n. 22, p. 367-384, jul/dez. 2009.

COX, K. The Problem Of Metropolitan Governance and The Politics Of Scale. Regional Studies, Abingdon, v. 44, n.2, p. 215-227, Mar. 2010.

CUNHA, J. M.; SILVA, K. A. A. S.; BECCENERI, L. B. (org.) Vale do Paraíba e Litoral Norte: diversidades socioespaciais. (Atlas NEPO). Campinas: Librum, 2019. E-book. Disponível em: https://www.librum.com.br/valelitoral/info/ . Acesso em: 07 fev. 2022.

EMPRESA PAULISTA DE PLANEJAMENTO METROPOLITANO [EMPLASA]. Quadro de Dados da Macrometrópole Paulista - MMP. Disponível em: https:// emplasa.sp.gov.br/. Acesso em: 05 out. 2019.

FERNANDES, F. A revoluçáo burguesa no Brasil. São Paulo: Globo, 2005.

FERRÁO, J. Governança, governo e ordenamento do território em contextos metropolitanos. In: FERREIRA, A. et al. (org.). Metropolização do espaço: gestão territorial e relaçôes urbano rurais. Rio de Janeiro: Consequência, 2013. p. 255-282.

FREY, K. Development, Good Governance, and its Implications for Local Democracy. Brazilian Political Science Review, São Paulo, v.2, n.2, p.39-73, Dec. 2008.

FREY, K. Governança urbana e participação pública. Revista de Administração Contemporânea, Maringá, v.1, p.136-150, 2007.

FREY, K. Governança interativa: uma concepção para compreender a gestão pública participativa? Política e Sociedade, Florianópolis, n.5, p.119-138, out. 2004.

FUNDAÇÃO SISTEMA ESTADUAL DE ANÁLISE DE DADOS [SEADE]. O Estado dos Municípios. São Paulo: SEADE, 2014.

GARSON, S. Regióes metropolitanas: por que não cooperam?. Rio de Janeiro: Letra Capital: Observatório das Metrópoles, 2009. 
GOMES, C.; RESCHILIAN, P. R.; UEHARA, A. Y. Perspectivas do planejamento regional do Vale do Paraíba e litoral norte: marcos históricos e a institucionalizaçáo da região metropolitana no Plano de Ação da Macrometrópole Paulista. Revista Brasileira de Gestáo Urbana, Curitiba, v. 10, n. 1, p. 154-171, 2018.

GRAMSCI, A. Cadernos do Cárcere. Rio de Janeiro: Civilização Brasileira, 2013. v.4.

GRUPPI, L. O conceito de hegemonia em Gramsci. Rio de Janeiro: Graal, 1978.

HAESBAERT, R. Regionalizaçóes brasileiras: antigos legados e novos desafios. Confins, Paris, n.44, 2020. Disponível em: http://journals.openedition.org/confins/ 26401. Acesso em: 7 fev. 2022.

KLINK, J. Development regimes, scales and state spatial restructuring: change and continuity in the production of urban space in metropolitan Rio de Janeiro. International Journal of Urban and Regional Research, Chichester, v.37. n.4, p.1168-87, 2013.

KLINK, J. (org.). Governança das Metrópoles: conceitos, experiências e perspectivas. São Paulo: Annablume, 2010.

KLINK, J.; DENALDI, R. On Urban Reform, rights and planning challenges in the Brazilian metropolis. Planning Theory, London, p.1-16, 2015.

LEFEBVRE, H. A Revolução Urbana. 5. ed. São Paulo: Centauro, 2008.

LEITÁO, K. O. A dimensão territorial do Programa de Aceleraçáo do Crescimento: um estudo sobre o PAC no estado do Pará e o lugar que ele reserva à Amazônia no desenvolvimento do país. 2009. 285f. Tese (Doutorado em Arquitetura) - Faculdade de Arquitetura e Urbanismo, Universidade de São Paulo, São Paulo, 2009.

LENCIONI, S. Metrópole, Metropolizaçáo e Regionalizaçáo. Rio de Janeiro: Consequência, 2017.

LENCIONI, S. O processo de metropolização do espaço: uma nova maneira de falar da relação entre metropolização e regionalização. In: SCHIFFER, S. R. (org.). Globalizaçáo e estrutura urbana. São Paulo: HUCITEC/FAPESP, 2004. p. 153165 .

LENCIONI, S. A emergência de um novo fato urbano de caráter metropolitano em São Paulo: a particularidade de seu conteúdo sócio espacial, seus limites regionais e sua interpretação teórica. In: ENCONTRO NACIONAL DA ANPUR, 10., 2003, Belo Horizonte. Anais [...], Belo Horizonte: ANPUR, 2003. p.1-13. 
LIMA, A. Região Metropolitana: Sim, nós podemos! Revista Vida Urbana, [s.l.], ano 2, n.9, p.12-17, ago. 2011.

MAGALHÂES, F (ed.). Regióes Metropolitanas no Brasil: um paradoxo de desafios e oportunidades. Washington: BID, 2010.

MARCONI, M. de A.; LAKATOS, E. M. Fundamentos de metodologia científica. 7.ed. São Paulo: Atlas, 2010.

MARGUTI, B. O.; COSTA, M. A.; FAVARÃO, C. B. (org.). Brasil metropolitano em foco: desafios à implementação do Estatuto da Metrópole. Brasília: IPEA, 2018.

MARIA, A.; DAVANZO, Q.; NEGREIROS, R. O fato metropolitano: desafios para a governança. Revista Paranaense de Desenvolvimento, Curitiba, p. 65-83, 2010.

MARICATO, E. Metrópoles desgovernadas. Estudos avançados, São Paulo, v.25, n.71, 2011.

MONTEMOR, R. L. O que é o urbano, no mundo contemporâneo. Revista Paranaense de Desenvolvimento, Curitiba, n.111, p.9-18, jul./dez. 2006.

MOTA, H. R. [Entrevista concedida a autor]. Jacareí, 11 de abril de 2019.

MULLER, N. L. O fato urbano na bacia do rio Paraíba: Estado de São Paulo. Rio de Janeiro: IBGE, 1969.

PASTERNAK, S.; BÓGUS, L. M. Macrometrópole paulista: estrutura sócioocupacional e tipologia dos municípios: Mudanças na primeira década dos anos 2000. Revista Brasileira de Estudos Urbanos e Regionais, São Paulo, v. 21, n. 2, p. 431, 11 abr. 2019.

RIBEIRO, L. C. Q.; SANTOS JR., O. A.; RODRIGUES, J. M. Estatuto da Metrópole: avanços, limites e desafios. Boletim Observatório das Metrópoles, n. 380, mar. 2015. Disponível em: https://www.observatoriodasmetropoles.net.br/ estatuto-da-metropole-avancos-limites-e-desafios/\#: - :text=A\%20Lei\%2013.089\%20 que $\% 20$ instituiu,dos $\% 20$ territ $\%$ C3\%B 3 rios $\% 20$ metropolitanos $\% 20$ do $\% 20$ Brasil.\&text $=\mathrm{O} \% 20$ texto\%20traz\%20uma $\% 20 \mathrm{an} \% \mathrm{C} 3 \%$ A1lise,limites\%20do\%20 Estatuto\%20da\%20Metr\%C3\%B3pole. Acesso em: 31 jan. 2022.

RIBEIRO-MOREIRA, P. MELLO, L. F. Desenvolvimento econômico, população e impactos ambientais: mudanças contemporâneas no extremo leste paulista. In: ENCONTRO NACIONAL DE ESTUDOS POPULACIONAIS, 17., Caxambu. Anais [...], Caxambu, 20 a 24 de setembro de 2010. p.01-18.

ROJAS, E.; CUADRADO-ROURA, J. R.; GUELL, J.M.F. (ed.). Gobernar las metropolis. Washington: Banco Interamericando de Desarollo, 2005. 
SANTOS, D. F.; FERNANDES, A. S. A.; TEIXEIRA, M. A. C. As Regióes Metropolitanas no Brasil e o problema Institucional de Cooperação: a trajetória das Regiōes Metropolitanas de Natal e Aracaju. Cadernos EBAPE.BR, São Paulo, v.9, p.368-382, 2013.

SÃO JOSÉ DOS CAMPOS. Instituto de Pesquisa, Administração e Planejamento de São José dos Campos (IPPLAN). Revisão do Plano Diretor de Sáo José dos Campos: Leitura técnica do Município para revisão do Plano Diretor: Caderno 2. São José dos Campos: IPPLAN, 2017. Disponível em: http://planodiretor.sjc.sp.gov. br/uploads/Anexo. Acesso em: 25 set. 2020.

SÁO PAULO (Estado). Secretaria de Planejamento e Desenvolvimento Regional. Caracterização Socioeconômica das Regiáo do Estado de Sáo Paulo: Região Metropolitana do Vale do Paraíba. São Paulo, out. 2013.

SILVA, M. P. da. [Entrevista concedida a autor]. São José dos Campos, 15 de fevereiro de 2020.

SOUZA, C. Regióes metropolitanas: reforma do regime político e vazio de governança. In: DINIZ, E. (ed.). Globalizaçáo, Estado e desenvolvimento: dilemas do Brasil no novo milênio. Rio de Janeiro: FGV, 2007. p. 235-261.

STORPER, M. Governing the large metropolis. Territory, Politics, Governance, Abingdon, v.2, n.2, p.115-134, 2014.

TAVARES, J. C. Planejamento Regional no Estado de São Paulo. EURE, Santiago, v.44, n.133, p. 344-367, Sep. 2018.

VIEIRA, E. T.; SANTOS, M. J., Desenvolvimento econômico regional, uma visão histórica e teórica. Revista Brasileira de Gestáo e Desenvolvimento Regional. Taubaté, v. 8, n. 2(8), 2012. p.344-369, 2012.

WATSON, V. The planned city sweeps the poor away...: Urban planning and 21st century urbanisation. Progress in Planning, Oxford, v. 72, n. 3, p. 151-193, 2009.

WORLD BANK. Governance and development. Washington D.C.: The World Bank, 1992.

Recebido em: 30 de março de 2021

Aprovado em: 10 de agosto de 2021 